\title{
YO NO LEÍA A PACO Y LOLA
}

Roxana Reyes Rivas

Desde que alcancé la edad adulta he estado feliz por el hecho de no haber tenido que usar Paco y Lola como libro de texto cuando aprendí mis primeras letras. Sin embargo, eso no me eximió de los sesgos de género a que las niñas se ven expuestas en el sistema educativo costarricense.

Para empezar, recuerdo cómo todos los niños y todas las niñas trabajábamos todo el año para recoger fondos para los regalos de la fiesta de la alegría. No obstante, tuve una maestra que siempre escogía los regalos más costosos y sofisticados para los niños; en cambio, las niñas siempre recibíamos un regalo que más parecía de consolación que la recompensa a igual trabajo.

Además, eran regalos relacionados con los deportes y esa desigualdad ahora me hace pensar que era el mensaje 
subyacente de desestímulo hacia la práctica de los deportes para las niñas.

También me viene a la memoria esa misma maestra advirtiéndonos que los hombres tenían más libertad que las mujeres y que por eso, las niñas debíamos comportarnos mejor.

Siguiendo con los deportes, también recuerdo que los juegos que se esperaba que las niñas jugáramos estaban devaluados frente a los que los niños practicaban. Por ejemplo, no estaba para nada permitido que las niñas jugáramos fútbol. Lo interesante fue que después de un tiempo un grupo de niñas decidimos jugar fútbol a pesar de que las maestras ponían el grito en el cielo. Personalmente, nunca he sido muy deportista, pero creo que me uní a ese grupo solamente para contradecir la restricción.

Por otra parte, también cabe mencionar que me tocó ir a la escuela en tiempos en que no se permitía usar pantalones, ni shorts debajo de las enaguas, de tal forma que era un suplicio tener a la maestra todo el tiempo advirtiéndonos que nos "sentáramos bien para que no se nos vieran los calzones». Por lo demás, siempre estábamos más presionadas para que nuestros uniformes lucieran más ordenados que los de los niños porque «las chiquitas se ven más lindas con el uniforme bien arregladito». Por supuesto, una manifestación de enojo de parte de una niña siempre encontraba el consabido «las chiquitas se ven muy feas enojadas».

Así pues, no basta con eliminar textos que reproduzcan roles limitantes para uno u otro género. El problema, como yo lo veo, es más complicado. Hay muchas maneras de hacer que las mujeres internalicemos funciones que obedecen a mandatos sociales. 
Estos mandatos sociales se transmiten por medio de actitudes y declaraciones ante las cuales muchas veces no estamos en capacidad, como niñas, de rebelarnos. La maestra o el maestro necesita desaprender muchos valores y representaciones que, inconsciente o conscientemente, le transmite a sus estudiantes.

A pesar de que se ha mejorado mucho en la eliminación de sesgos de género en los textos escolares, todavía queda mucho por hacer. Aún hoy día conozco casos de niñas que han tenido que enfrentar obstáculos para poder practicar el deporte de su preferencia porque la escuela en que estudian no estimula la práctica de dicho deporte entre las niñas.

Hace unos días mostrándole a una amiga extranjera la romería hacia la Basílica de los Ángeles, pude ver muchas niñas y muchos niños en uniforme, en compañía de sus maestras visitando la Basílica. Ciertamente soy una persona respetuosa de la devoción a la Virgen de los Ángeles, pero me inquieta que la escuela tenga todavía la tarea de reproducir los valores religiosos a tan tierna edad. Si en el seno familiar éstos se transmiten, esa es una decisión posiblemente inobjetable, pero hacerlo desde la escuela es mantener sesgos de género dentro de la educación formal.

Por mucho que digan las devotas y los devotos de la diosa, que esa es una recuperación del antiguo culto, como yo lo veo, el culto mariano, tal y como lo transmite la Iglesia Católica, poco tiene de positivo para las mujeres. María sigue siendo la imagen de la mujer sacrificada y doliente que recibe su valor a la sombra de un hombre, su hijo. Las niñas siguen recibiendo los mismos mensajes acerca de su valor y lo que se espera de ellas mediante la educación religiosa dentro del sistema educativo costarricense. 
No sé cuántos maestros y cuántas maestras siguen repitiendo las cosas que oí de las mías. Tampoco sé si las escuelas de educación en nuestras universidades ofrecen alguna motivación a los y las estudiantes para que cuestionen los prejuicios y valoraciones aprendidas en una sociedad sexista. Lo que sí se es que muchos maestros y muchas maestras fueron estudiantes en la misma época en que yo lo fui. También sé que muchas de estas personas se sienten depositarias de la obligación de mantener un estado de cosas que, a su vez, mantiene un orden social discriminatorio ya establecido. A su vez, entiendo que muchas de estas personas que sí han podido desaprender muchos de los peores valores de nuestra sociedad se sienten profundamente presionadas por un sistema y una sociedad que les exige una forma específica de ser y de ejercer sus funciones.

Por consiguiente, modificar el sistema de educación y alcanzar una educación más justa en términos de género requiere un cambio más profundo, en las raíces mismas de nuestra sociedad. Alcanzar una educación no sexista supone una educación verdaderamente laica, una sociedad tolerante y respetuosa que respalde un estado y exija un gobierno acorde. Estamos acaso en condiciones de lograr todo eso? 